\title{
New prostate cancer grade group system correlates with prostate cancer death in addition to biochemical recurrence
}

\author{
Jonathan I Epstein ${ }^{\star, 1}$ \\ ${ }^{1}$ Department of Pathology, Urology, Oncology, The Reinhard Professor of Urological Pathology, The Johns Hopkins Medical \\ Institutions, Baltimore, MD 21231-241, USA
}

The study by Berney et al (2016) is an important work correlating prostate cancer death with the new 5 Grade Group system for prostate cancer. The novel Grade Group system was first proposed by the group from Johns Hopkins Hospital in 2013 (Pierorazio et al, 2013) and subsequently validated with a multi-institutional study by Epstein et al (2016a) of over 20000 men treated by radical prostatectomy and over 5000 men who underwent radiation therapy using biochemical recurrence as the end point.

The study by Berney et al (2016) is the first to demonstrate that the 5 Grade Groups also correlate well with death due to prostate cancer, further validating the veracity of the new grading system. As noted by the authors, there are inherent weaknesses in the Transatlantic Prostate Group cohort used in the Berney et al study, as cases were included from as far back as 1990, when diagnosis and treatment of prostate cancer was very different than current practice. For example, sextant core biopsy was the most common biopsy technique used in the study by Berney et al (2016), which is now recognised as suboptimal sampling of the prostate. However, the advantage of using these older cases is that there is sufficient follow-up that the study could assess death from prostate cancer.

This study also evaluates the controversial issue of whether the extra effort of calculating average grade on biopsy when there are multiple different cores with different grades adds significantly to predict prognosis as opposed to using the highest grade. In the United States, the typical practice is to assign a grade to each involved core and leave it up to the clinician to determine the grade used for treatment and prognosis, typically the core with the highest grade. The highest grade on a given core has been used for generating popular predictive and prognostic tools, such as the Kattan nomograms and the Partin tables. However, some pathologists in other countries have advocated for adding all the positive cores together as if it was one long core to determine the 'average' or 'global' Gleason score for the case. A more complicated and subjective variation on 'average' Gleason score has been proposed by some pathologists where there they average together only some of the positive cores together based on their location and grade in an attempt to determine which is the dominant tumour nodule grade (Arias-Stella et al, 2015). It is my practice to give the individual core grades and leave it up to the clinician to determine the grade for treatment and prognosis. It may be the highest grade on a given core or the clinician may have information on the dominant tumour location by multiparametric MRI and targeted biopsies, which could be factored in for determining the dominant tumour nodule grade. The pathologist does not always have access to the results of imaging procedures. The study by Berney et al (2016) demonstrates that using the worst grade in a case, as opposed to the 'average' grade, resulted in greater separation of Grade Groups 3 and 4. The worst grade was also used in both the initial and validating studies of Grade Groups (Pierorazio et al, 2013; Epstein et al, 2016a), which showed significant differences in biochemical recurrence between Grade Groups 3 and 4.

Berney et al (2016) add to the growing body of literature on the validity of the new simplified Grade Group system for prostate cancer. There are several advantages of the new system. First, it is a more accurate grade stratification than current applications of the Gleason system. The second major benefit of the new grading system is it is simple and intuitive, ranging from 1 to 5 as opposed to the current application of the Gleason system which in practice ranges from 6 to 10 , and includes 7 that is separated into $3+4=7$ and $4+3=7$. The new grading system and its terminology 'Grade Groups 1-5' were also adopted by the 2016 Edition of the World Health Organization of the Pathology and Genetics: Tumours of the Urinary System and Male Genital Organs. For the foreseeable future to ease the transition to the new grading system, it was agreed upon that both the Gleason grade and the Grade Groups would be included in pathology reports (Epstein et al, 2016b). 


\section{REFERENCES}

Arias-Stella 3rd JA, Shah AB, Montoya-Cerrillo D, Williamson SR, Gupta NS (2015) Prostate biopsy and radical prostatectomy Gleason score correlation in heterogenous tumors: proposal for a composite Gleason score. Am J Surg Pathol 39: 1213-1218.

Berney DM, Beltran L, Fisher G, North BV, Greenberg D, Moller H, Soosay G, Scardino P, Cuzick J (2016) Validation of a contemporary prostate cancer grading system using prostate cancer death as outcome. Br Jnl Cancer 114: 1078-1083.

Epstein JI, Zelefsky MJ, Sjoberg DD, Nelson JB, Magi-Galluzzi C, Vickers AJ, Parwani VE, Fine SW, Eastham JA, Wiklund P, Han M, Reddy CA, Ciezki JP, Nyberg T, Klein EA (2016a) A contemporary prostate cancer grading system: a validated alternative to Gleason score. Eur Urol 69: 428-435.
Epstein JI, Egevad L, Amin MB, Delahunt B, Srigley JR, Humphrey PA. Grading committee (2016b) The 2014 International Society of Urological Pathology (ISUP) Consensus Conference on Gleason Grading of Prostatic Carcinoma: definition of grading patterns and proposal for a new grading system. Am J Surg Pathol 40: $244-252$.

Pierorazio PM, Walsh PC, Partin AW, Epstein JI (2013) Prognostic Gleason grade grouping: data based on the modified Gleason scoring system. BJU Int 111: 753-760.

(c) (1) (2) This work is licensed under the Creative Commons BY No At Atribution-Non-Commercial-Share Alike 4.0 International License. To view a copy of this license, visit http:// creativecommons.org/licenses/by-nc-sa/4.0/ 